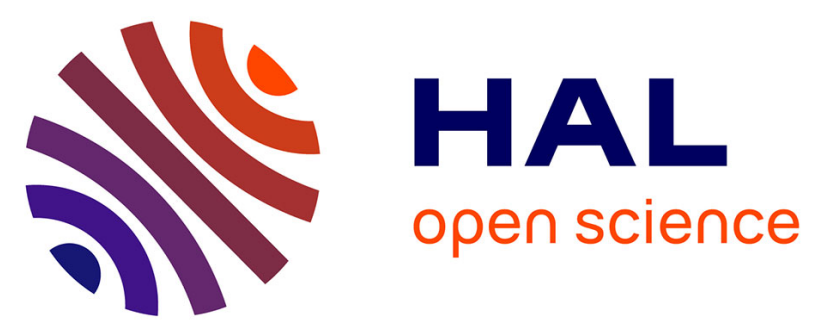

\title{
Intact NMR spectroscopy: slow high-resolution magic angle spinning chemical shift imaging
}

Covadonga Lucas-Torres, Alan Wong

\section{To cite this version:}

Covadonga Lucas-Torres, Alan Wong. Intact NMR spectroscopy: slow high-resolution magic angle spinning chemical shift imaging. Analyst, 2020, 145, pp.2520-2524. 10.1039/D0AN00118J . cea02504285

\section{HAL Id: cea-02504285 \\ https://hal-cea.archives-ouvertes.fr/cea-02504285}

Submitted on 9 Dec 2020

HAL is a multi-disciplinary open access archive for the deposit and dissemination of scientific research documents, whether they are published or not. The documents may come from teaching and research institutions in France or abroad, or from public or private research centers.
L'archive ouverte pluridisciplinaire HAL, est destinée au dépôt et à la diffusion de documents scientifiques de niveau recherche, publiés ou non, émanant des établissements d'enseignement et de recherche français ou étrangers, des laboratoires publics ou privés. 


\title{
Intact NMR spectroscopy: slow high-resolution magic angle spinning chemical shift imaging
}

\author{
Covadonga Lucas-Torres, Alan Wong*
}

High-Resolution Magic-Angle Spinning Chemical Shift Imaging (HRMAS CSI) has recently been explored for nuclear magnetic resonance (NMR) metabolomics and showed a considerable promise in organism research. This is owing to its capability of offering a supplemental dimension - spatial metabolic distribution - in the profiling. However, HR-MAS CSI suffers from the large centrifugal stress exerted onto the sample, which inevitably hinders the metabolic assessments. Herein, a slow sample spinning strategy was implemented and evaluated. The results demonstrate a potential - with high quality data and feasibility - as a highly informative profiling approach to intact specimens.

Metabolomics is one of the significant OMICS fields which study the chemical profiles of the low-molecular weight metabolites $(<1 \mathrm{kDa})$ those responses to the metabolism of interest. It plays a vital role of untangling many biocomplexities in life sciences. ${ }^{1}$ This is, in fact, the consequence of the vast advancement of bioanalytical technologies; they play a significant role on the development of metabolomics. Among them, NMR spectroscopy has found tremendous success due to its simplicity and versatility of acquiring unbiased and rich metabolic information on diverse biospecimens. In particular, High-Resolution Magic-Angle Spinning (HR-MAS) is a valuable NMR tool for profiling the metabolic constituents inside the heterogeneous specimens such as whole cells and organisms, and tissues. It benefits from the capacity of offering high spectral quality data by rapidly rotating the sample at a $54.74^{\circ}$ (magic-angle) to the NMR magnetic field. This suppresses the unwanted magnetic susceptibility line broadening ascribed within the sample. For this reason, HR-MAS NMR is a wellestablished technique and vastly applied. This includes intact NMR studies of a single mm-scaled organism, ${ }^{2}$ and even a smallscaled animal. ${ }^{3}$ However, despite its versatility, HR-MAS only offers a global metabolic view of the entire organism, masking the profiles of the specific anatomy.

Recently, an advanced development of HR-MAS methodology - with chemical shift imaging (CSI) - has been introduced $^{2 b}$ and explored ${ }^{4}$ towards metabolomics. HR-MAS CSI offers an additional spatial dimension for the possibility of a homogeneous profiling (i.e. localized spectroscopy along the sample rotational axis) from a heterogeneous specimen such as an intact organism. The experiment is taking advantage of the sample spinning with HR-MAS for providing the essential high quality spectral data, and a gradient field for localizing the metabolic profiles along the rotational axis z' (magic-angle axis). Indeed, the capability of simultaneous profiling the different anatomies in a single HR-MAS CSI experiment should offer a valuable analytical approach for intact study of an organism. However, the induced centrifugal stress by MAS exerted onto the organism can inevitably disrupt the metabolic profiles (i.e. change in the metabolic activities or even in the morphology). A common strategy for subsiding the stress is by reducing the sample spinning. For example, spinning the sample at $500 \mathrm{~Hz}$ instead of $5000 \mathrm{~Hz}$ would reduce the force by two-order of magnitude. However, the issue is the presence of the dense spinning-sideband manifolds on the spectrum (denoted as ssb), which can complicate the analysis and, sometimes, impossible. Most efforts on slow spinning HR-MAS have been focusing on suppressing these ssb by (i) manipulating the rotor-phases in the pulse-experiments, ${ }^{5}$ (ii) improving the water suppression efficiency, ${ }^{6}$ (iii) utilizing the isotope ${ }^{2} \mathrm{H}$ detections, ${ }^{7}$ (iv) optimizing the sample preparations ${ }^{8}$ and by (v) spectral manipulation. ${ }^{9}$

This study intends to improve the HR-MAS CSI strategy for intact NMR spectroscopy by incorporating a slow sample spinning experiment together with the use of the integrated homospoil z'-gradient (for improving the feasibility). Both have yet to be explored. The experimental design is discussed and applied to a food phantom and an intact insect wasp (Vespula germanica). The detail descriptions of the experimental strategies and results will offer the basis for designing future intact studies with slow sample spinning HR-MAS CSI.

The integration of HR-MAS CSI pulse experiment with a ssb suppression is facilitated by the spin-echo nature in both experiments. It can be achieved by replacing the refocusing $\pi$ pulse in CSI with a set of rotor-period composite $\pi$ pulses (see Fig. S1). A major concern for metabolomics is the length of the experiment carrying out on susceptible specimens. This is especially of importance for a two-dimensional (2D) HR-MAS CSI with the chemical shift profile in $\mathrm{F} 2$ and the spatial profile in F1. As such, HR-MAS CSI can be a time demanding experiment. It depends on the number of $\mathrm{t} 1$ spatial encoding (denoted herein as $\mathrm{t} 1 \mathrm{CSI}$ ), and the detection sensitivity (i.e. metabolic abundance). Therefore, the choice of implementing the ssb suppression experiment must not dramatically lengthen the acquisition.

Total Suppression of Sidebands (TOSS) is a 1D ssb suppression experiment ${ }^{10}$ and should be a beneficial facto to the integration; however, TOSS is highly susceptible to the imperfection of the $\pi$ pulses and the instabilities of the spinning. Both can result in distorted spectral. ${ }^{11}$ An extensive 243-steps phase cycling scheme are often necessary to overcome the effect of the pulse imperfections, ${ }^{12}$ and has successfully applied to intact specimens. ${ }^{6}$ 
The current preferred ssb suppression is a pseudo-2D PhaseAdjusted Spinning Sidebands (PASS), ${ }^{13}$ with $\mathrm{t} 1$ associated to the signal evolution of the $s s b$ (denoted herein as $t 1_{\text {PASS, }}$ often with 8,16 or 32 increments). Despite its 2D nature, PASS, in general, has better resistance to the pulse imperfection as compared to TOSS, ${ }^{11}$ rendering a more effective approach with a less strenuous phase cycling scheme. ${ }^{5}$ This includes an 11-steps cogwheel phase cycling scheme. ${ }^{14} \mathrm{Fig}$. $\mathrm{S} 2$ shows the results of PASS with an 11-steps phase cycling.

This study incorporates the PASS experiment into the HRMAS CSI (denoted herein as HR-PASS CSI) with an 11-steps cogwheel phase cycling scheme. HR-PASS CSI is essentially a pseudo-3D experiment by acquiring a series of individual 2D CSI spectra, each with an identical $t 1_{\mathrm{CSI}}$ spatial encoding but with different $t 1_{\text {pass }}$ steps. In this study, an 8-steps t1 pass is applied. As a result, the total acquisition time of HR-PASS CSI can be estimated with $(11 \times 8) \cdot 1_{\text {CSI. }}$ This is significantly shorter than that of an incorporation with TOSS, (243) $\cdot \mathrm{t} 1_{\mathrm{CSI}}$.

In contrast to the previous HR-MAS CSI experiments, ${ }^{2 b, 4}$ this study also explores the convenience of the experimental setup by exploiting the integrated homospoil gradient field $\mathrm{G}_{z}$ (along the magic angle $z^{\prime}$ ) of a conventional HR-MAS probe, without an external pulsed field gradient (PFG) system. In general, homospoil generates a weaker gradient field (and less durable) as compared to PFG; however, the field efficiency is compensated by the proximity to the sample. But one cautious note should be considered when applying the homospoil gradient. The duty cycle (the fraction of the pulse in one acquisition) should not exceed the specification limit. ${ }^{15}$

As shown in Fig. S1b, rotor synchronization periods $\left(\tau_{R}\right)$ are carried out throughout the pulse experiment - the echo delays (TE), the $5 \pi$ PASS pulses and the gradient pulse ( $\delta$ ). Consequently, this study limits the spinning frequency to $500 \mathrm{~Hz}$ and renders a fixed value of $2 \mathrm{~ms}$ for $\delta$ in the experiments. Subsequently, the field-of-view (FOV) in CSI is regulated by the gradient amplitude $\left(\mathrm{G}_{\mathrm{Z}}\right)$ and the $\mathrm{t} 1_{\mathrm{CSI}}$ encoding $\left(\mathrm{FOV}=\left[\mathrm{t} 1_{\mathrm{CSI}}\right] \times\right.$ $\left[k \cdot{ }^{1 H_{Y}} \cdot \delta \cdot G_{Z}\right]^{-1}$, where $\mathrm{k}$ is a scaling factor and $\gamma$ is the ${ }^{1} \mathrm{H}$ frequency).

Food tissue is an excellent phantom to evaluate the capability of metabolic profiling with HR-PASS CSI owing to their uniform distributions of the metabolites in the tissue and, as necessary, it offers superior signal resolutions. The phantom consists of four distinct layers [zucchini (or courgette) - garlic apple - ground peanuts], each with a thickness of $\sim 1 \mathrm{~mm}$, placed transversely at the centre of the rotor. A single thin individual green leaf (of about $20 \mu \mathrm{m}$ in thickness) is strategically placed between the layers of zucchini and garlic, and garlic and apple to evaluate the spatial separation by HRPASS CSI.

As shown in Fig. 1a, both HR-MAS CSI and HR-PASS CSI exhibit a 2D spectrum with a spatial $\mathrm{z}^{\prime}$ distribution (in $\mathrm{mm}$ ) along $\mathrm{F} 1$, separating the individual sliced spectral profiles (in ${ }^{1} \mathrm{H} \delta$ ppm) in F2. Experimental details can be found in ESI. Both experiments were acquired with identical spatial encoding parameters, with a FOV of $8.3 \mathrm{~mm}$ attributed by a $64 \mathrm{t} 1_{\mathrm{CSI}}$ and $10 \%$ of $\mathrm{G}_{\mathrm{z}}$. This results in a slice resolution $\Delta \mathrm{S}$ (FOV / $\left.\mathrm{t} 1_{\mathrm{CSI}}\right)$ of $0.13 \mathrm{~mm}$. As expected the acquisition time for HR-PASS CSI is 8 times longer ( $\left.8 \mathrm{t} 1_{\text {PASS }}\right)$ with a duration of two hours. However, based on the well-defined spatial profile (Fig. S3), the data acquisition could readily shorten by half (or more) with $32 \mathrm{t} 1_{\mathrm{cS} \text {, }}$ which doubles the $\Delta S$ to $0.26 \mathrm{~mm}$.

The HR-MAS CSI spectra (Figs. 1a and S4) reveal highly congested spectra with ssb signals masking some significant metabolites. For example, a large ssb appears at $6 \mathrm{ppm}$ in the slice spectra associated with the garlic layer has overlapped with a set of multiplets of organosulfur allicin. In contrast, the results from HR-PASS CSI exhibit ssb-free spectra with isotropic metabolic signals. With one exception, a single ssb signal of the fatty acid methylene resonance is observed. This is ascribed from the large fatty acid content in the peanut layer. The stacked plot of the slice spectra in Fig. S5 shows distinct profiles among the different food layers. This is also supported by a principal component analysis. The superior peak resolution (with $<0.02 \mathrm{ppm}$ ) allows for a rich metabolic identification for each layer (Tables S1-S2). It is noteworthy that a subsequent fast sample spinning $(4000 \mathrm{~Hz})$ HR-MAS CSI has been carried out (Fig. S5), and showed a dramatic change in the spectral profile for the individual layers, indicating a displacement of the metabolic fluids among the layers.

Exploiting the superior spectral quality data, a heatmap of the relative metabolic content $\left(R_{\text {met }}\right)$ along the $z^{\prime}$ is constructed (Fig. 1b). For each slice spectrum, $R_{\text {met }}$ can be estimated by the individual metabolic integral $\left(I_{\text {met }}\right): R_{\text {met }}=\left[100 \% \times I_{\text {met }}\right] /\left[\mathrm{N}_{\mathrm{H}-\mathrm{met}}\right.$ $\times I_{\text {spectral sum] }}$, where $\mathrm{N}_{\mathrm{H} \text {-met }}$ is the number of corresponding protons, and $I_{\text {spectral sum }}$ is the total integral between $0.5-8.5 \mathrm{ppm}$ excluding the water signal. This is followed by a colour coding scheme with red being the highest content and blue at zero. Subsequently, each colour box along $z^{\prime}$ corresponds to $\Delta \mathrm{S}$. The heatmap displays a few hidden variances that are not evident from the spectra. For examples, it reveals the different sugar distributions in the layers; allicin in the garlic layer; alanine, glutamine and fumarate in the zucchini layer; and the fatty acids 
associated within the thin layer of the green leaf (more discussion below).
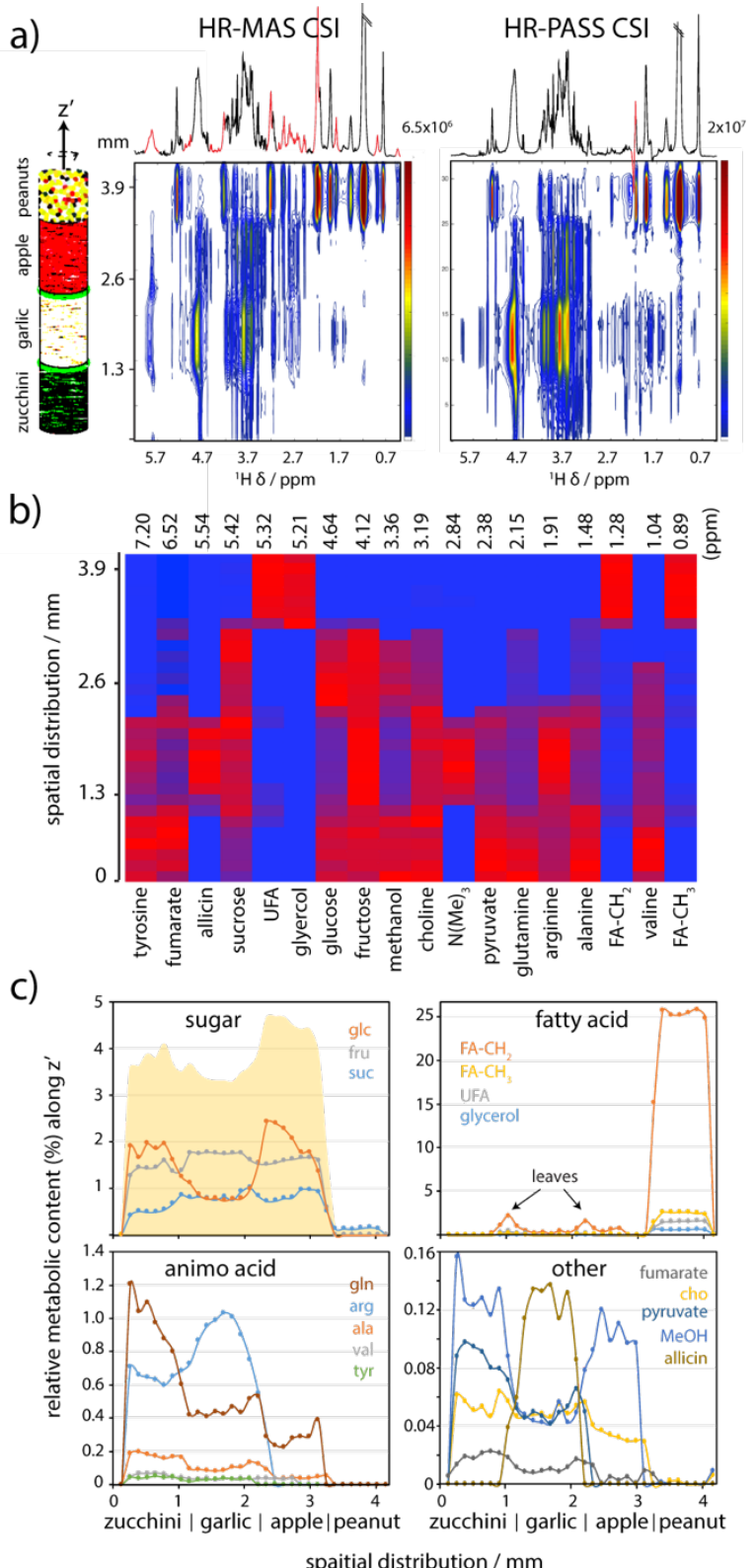

Fig. $1^{1} \mathrm{H}$ CSI spectra of a food phantom at $11.75 \mathrm{~T}$ with a sample spinning at $500 \mathrm{~Hz}$ and with a TE of $8 \mathrm{~ms}$. Experimental detail can be found in ESI. (a) 2D contour plots of HRMAS CSI and HR-PASS CSI with the $z^{\prime}$ spatial distribution (in $\mathrm{mm}$ ) along $\mathrm{F} 1$ and the localized ${ }^{1} \mathrm{H}$ chemical shifts (in ppm) along F2. The F2 projection of HR-MAS CSI shows a highly congested spectrum with the ssb (highlight in red); however, HR-PASS CSI shows the contrary. (b) A heatmap showing the estimated relative metabolic content $\left(R_{\text {met }}\right)$ along $z^{\prime}$. The description of $R_{\text {met }}$ is discussed in the text. Each colour box along $z^{\prime}$ corresponds to a $\Delta S$ of $0.13 \mathrm{~mm}$ with red represents the highest metabolic content and blue represents zero. (c) Heatmap z' projection of the individual metabolite showing the metabolic distributions across the different food layers. The shaded area in the sugar plot represents the sum $R_{\text {glc }}+R_{\text {fru }}+R_{\text {suc }}$.

The $z^{\prime}$ projection of the heatmap (Fig. 1c) shows a greater extent of the metabolic distributions across the layers. Among the NMR observable metabolites, sugars comprise the highest - excluding fatty acids - metabolic content (ca. 1-2 \%). The plot exhibits an apparent variation among the common natural sugars (sucrose, fructose and glucose) in the food tissues.
Moreover, it discloses that the apple layer consists of the highest total sugar level (i.e. sweetest among the layers) as compared to that of the garlic with the lowest. For fatty acids, the peanut layer, as excepted, consists of the highest content. However, a small - but visible - increased level of fatty acids can be located in between the food layers (zucchini | garlic and garlic | apple). Similarly, a subtle increased of choline is also found at the same $z$ ' location. These increased contents are associated with the green leaves between the layers. Since the acquired $\Delta \mathrm{S}, 130 \mu \mathrm{m}$, is much greater than the leaf thickness $\sim 20 \mu \mathrm{m}$, the observed metabolic signals (including the fatty acids and choline $^{16}$ and others) are expected to overlap with the neighbouring profiles.

To illustrate the feasibility of HR-PASS CSI to a single intact organism, Figs. 2 and $\mathrm{S} 6$ show the resultant spectra of an insect wasp. The data were acquired with a $\Delta \mathrm{S}$ of $0.26 \mathrm{~mm}$ and with a total acquisition time of 70 minutes. No visible body damage (or fluids) is found after the experiment. Experimental details can be found in ESI. The insect diameter (ca. $3.0 \mathrm{~mm}$ ) is similar to the inner rotor diameter. This allows securing the insect with the longitudinal body axis aligned with the $z^{\prime}$, and permits for profiling the transverse plane of the distant anatomical sections of a wasp: tail, mid and head. The resultant HR-PASS CSI spectra were collected with a $T_{2}$-contrast $(T E=100 \mathrm{~ms})$. The benefits with a $\mathrm{T}_{2}$-contrast experiment on the wasp are shown in Fig. S6b. The long TE: (i) improves the spectral bassline by removing the broad signals of the macromolecules such as proteins; (ii) improves the water suppression and sequentially minimizes (or even eliminates) the residual ssb; and as importantly, (ii) enhances the metabolic signals by suppressing fatty acid signals (e.g. $0.86 \mathrm{ppm}, 1.24 \mathrm{ppm}, 1.59 \mathrm{ppm}$...) and ssb. It is noteworthy that if a $\mathrm{T}_{2}$-contrast experiment (instead of $8 \mathrm{~ms}$ ) was applied to the food phantom above (Fig. 1a), it would probably subside the observed ssb of the methylene fatty acid.

About 20 metabolites are tentatively identified (Table S3), and a few resolved metabolic signals are exploited in the heatmap analysis (Figs. 2 and S7). The corresponding $z^{\prime}$ projection reveals the individual metabolic profile across the anatomical sections. The results show that the tail consists of a higher content of fatty acid as compared other sections. Interestingly, it also able to locate the venom region within the tail. Based on the heatmap analysis, the size of the venom region is about $1 \mathrm{~mm}$ along $z^{\prime}$. It is known that venom contains three significant metabolites: ${ }^{17}$ (1) amine-derivatives (such as histamine) involves in the inflammatory response by increasing the permeability of blood capillaries; (2) serotonin plays a role in irritation and contributes to pain; and (3) acetylocholine increases the perceived pain. Fig. 88 shows the presence of the acetylcholine and serotonin signals in the slice spectrum of the venom region. The unassigned peaks at 8.34 and $7.27 \mathrm{ppm}$ could be related to the physiologically active amine derivatives in the venom.

In the mid-section, HR-PASS CSI reveals a high level of taurine and betaine (Fig 2). Interestingly, there is also a variance in the sugars. While, both glucose and fructose are significant in the head and tail sections, but only a hint of glucose is found in 
the mid-section. These observed differences could relate to the different in blood metabolisms ${ }^{18}$ in the different anatomy.

a)

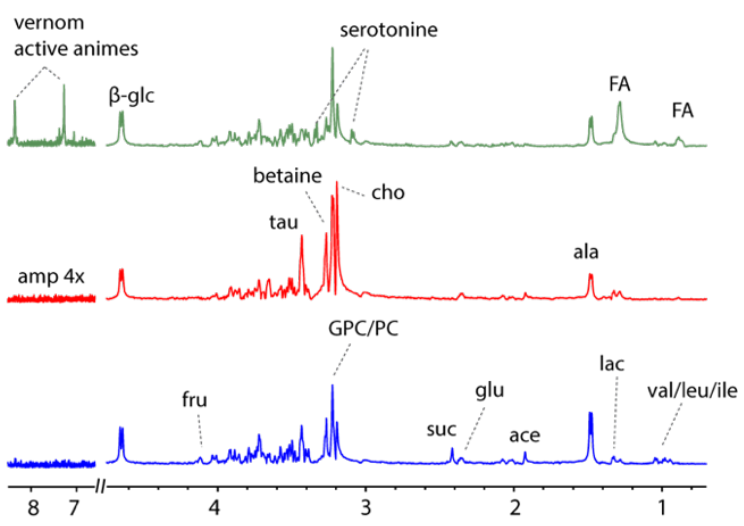

b)

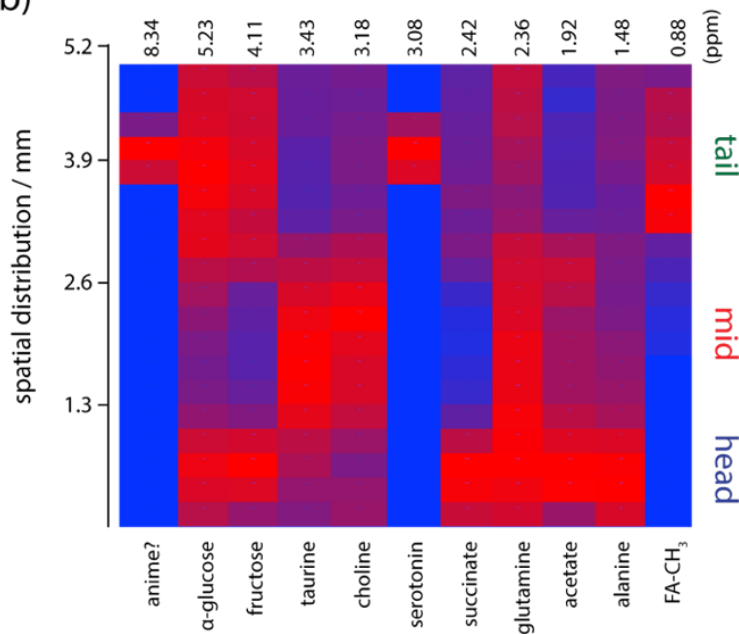

Fig. 2 (a) Representative F2 slice projection spectra of HR-PASS CSI (spinning at $500 \mathrm{~Hz}$ with a TE of $100 \mathrm{~ms}$ ) for each anatomical section: green-tail; red-mid; blue-head. The projections are indicated by the dotted line in the 2D spectrum in Fig. S6a. Peak assignments are summarized in Table S3. (b) Heatmap showing the metabolic variations across the different anatomies. Each box along $z^{\prime}$ corresponds to a $\Delta S$ of $026 \mathrm{~mm}$ with red represents the highest metabolic content and blue represents zero. The $z^{\prime}$ projections are shown in Fig S7.

To evaluate the reproducibility of HR-PASS CSI experiment, an experiment with identical setup (spatial encoding and PASS evolutions) was performed on a second wasp individual (WASP \#2). The heatmap analysis exhibits similar metabolic distributions across the anatomical sections (Fig. S7). Of course, more experiments and data are necessary to reaffirm the reproducible quantification of HR-PASS CSI profiling. Nevertheless, the results shown here offer a promising potential to metabolomic study of intact organisms.

The experimental strategy present here with HR-PASS CSI can be considered as an incremental - but significant improvement to the previous HR-MAS CSI. It offers both spatial and chemical information on a conserved intact specimen. HRPASS CSI could render a potent metabolic NMR profiling approach to organism research. This study provides the basis for designing intact NMR metabolomics. As importantly, it also offers the fundamentals for incorporating additional spinedited pulse experiments - such as diffusion or X-spin filtered - prior to HR-PASS CSI. Moreover, the PASS sequence could also be readily implemented in $1 \mathrm{D}$ slice localized spectroscopy ${ }^{[2 \mathrm{~b}]}$ for a direct profiling on a specific region of interest. This would permit a quick data acquisition and further enhances the conservation of the specimens, but the drawback is a prior knowledge of the spatial region of interest is necessary.

HR-PASS CSI could provide a new prospective for intact NMR-based metabolomics of research organism. The abilities of (i) unfolding the specific metabolic profiles from a heterogeneous specimen; and (ii) simultaneous profiling the different autonomic regions should provide a vital parallel investigation on the concurrent metabolic activities of interest, offering in-depth insights in life sciences.

All spectra data were acquired on a $500 \mathrm{MHz}$ Bruker Avance II equipped with a conventional Bruker 4-mm HR-MAS probe. The detailed description of the experiment can be found in ESI. The study was supported by the French Agence Nationale de la Recherché (ANR-16-CE11-0023-01).

\section{Conflicts of interest}

Authors declare there are no conflicts to declare.

\section{Notes and references}

1 J. K. Nicholson, I. D. Wilson ID, Nat. Rev. Drub Discov., 2003, 2, 668.

2 (a) M. Bastawrous, A. Jenne, M. T. Anaraki, A. J. Simpson, Metabolites, 2018, 8, 35; (b) V. Sarou-Kanian, N. Joudiou, F. Louat, M. Yon, F. Szeremeta, S. Même S, et al. Sci Rep. 2015, 5, 1-5; (c) V. Righi, Y. Apidianakis, D. Mintzopoulos, L. Astrakas, L. G. Rahme, A. A. Tzika, Int. J. Mol. Med. 2010, 26, 175.

3 R. A. Wind, J. Z. Hu, D. N. Rommereim, Magn. Reson. Med., 2003, 50, 1113-9.

4 A. Wong, C. Lucas-Torres, Anal. Bioanal. Chem., 2019, 411 1591.

5 R. A. Wind, J. Z. Hu, Prog. Nucl. Magn. Reson. Spectrosc., 2006, 49, 207.

6 Y. L. Mobarhan, J. Struppe, B. Fortier-McGill, A. J. Simpson, Anal. Bioanal. Chem. 2017, 409, 5043.

7 Y. L. Mobarhan, R. Soong, W. Bermel, M. J. Simpson, J. Struppe, H. Heumann, S. Schmidt, H. Boenisch, D. Lane, A. J. Simpson, ACS Omego 2018, 3, 17023.

8 M. Renault, L. Shintu, M. Piotto, S. Caldarelli, Sci. Rep., 2013, 3, 3349.

9 M. A. Burns, J. L. Taylor, C-L. Wu, A. G. Zepeda, A. Bielecki, D. Cory, L. L. Cheng, Magn. Reson. Med., 2005, 54, 34.

10 W. T. Dixon, J. Magn. Reson., 1981, 44, 220.

11 J. Z. Hu, R. A. Wind, J. Magn. Reson., 2002, 159, 92.

12 O. N. Antzutkin, M. H. Levitt, J. Magn. Reson. Series A, 1996, 118, 295.

13 O. N. Antzutkin, S. C. Shekar, M. H. Levitt, J. Magn. Reson., 1995, A115, 7.

14 N. Ivchenko, C. E. Hughes, M. H. Levitt, J. Magn. Reson., 2003, 164, 286.

15 The upper limit for a Bruker HR-MAS probe is suggested to be of $\sim 4 \mathrm{~ms}(\delta)$ at $70 \%\left(\mathrm{G}_{\mathrm{z}}\right)$ of a $10 \mathrm{~A}$ amplifier.

16 D. Augustijn, U. Roy, R. van Schadewijk, H. J. M. de Groot, A. Alia, PLOS ONE, 2016, DOI:10.1371/journal.pone.0163258

17 M. Moreno, E. Giralt, Toxins (Basel), 2015, 7, 1126.

18 R. D. Fell, Camp. Biochem. Physiol., 1990, 95A, 539. 
Electronic Supplementary Information

Intact NMR spectroscopy: slow high-resolution magic angle spinning chemical shift imaging

\section{NMR Experiment}

Experimental details $\quad$ p2

Fig S1. Pulse experiments $\quad$ p4

Fig S2. Slow sample spinning spectra with different phase-cycling schemes p5

\section{Food phantom}

Fig S3. 1H density F1 projection of the food phantom p6

Fig S4. Spectra comparison of the individual food layers $\quad$ p7

Fig S5. Spectral [F2 and F1] and PCA comparison of fast and slow CSI p8

\section{Intact wasp}

Fig S6. 2D spectrum and its comparison with different TE in HR-PASS CSI p9

Fig S7. Heatmap comparison between two individual wasp \#1 and \#2 p10

Fig S8. Spectral fitting on the venom metabolites p11

\section{Peak assignment}

Table S1. Metabolites in the food phantom p12

Table S2. Fatty acids in the peanut layer $\quad$ p13

Table S3. Intact wasp (tail, mid, head) $\quad$ p14

Table S4. Chemical shift range used for the heatmap analysis p15 


\section{Experimental Details}

\section{Sample preparation}

The samples were packing into a standard 4-mm $\mathrm{ZrO}_{2}$ rotor with an internal spacer at the bottom. A top Kel-F insert was used to secure the samples. No buffer or $\mathrm{D}_{2} \mathrm{O}$ were added to avoid the displacement of metabolites during the sample spinning.

Food phantom: The phantom (Fig 1a) with fresh local food layers was prepared by punching the individual pre-sliced layer (ca. $1 \mathrm{~mm}$ ) with the open-edge rotor.

Wasp: Three individual wasps was caught locally - within few minutes apart - and immediately snap-freeze and stored under $-80{ }^{\circ} \mathrm{C}$ until the acquisition. The frozen wasp was placed entirely inside the rotor with the head at the bottom. The body dimensions of the three wasps were nearly identical with $3 \mathrm{~mm}$ in diameter. This allowed a tight fix inside the rotor preventing body movement during the spinning. Among the three wasps, one was sacrificed for setting up the experiments: from field shimming, testing the phase cycling schemes (Fig S2) to setting up the spatial encoding parameters and the different TE (Fig S6). Other two wasps (WASP \#1 and \#2) were used to evaluate the HR-PASS CSI experiment and its data reproducibility (Fig S7). Spectra data of WASP \#1 were discussed in the text (Fig 2). It should be noted that no visible destructions (or fluids) on the body were found after the HR-PASS CSI experiment.

\section{NMR experiments}

${ }^{1} \mathrm{H}$ experiments were performed on a Bruker Avance II spectrometer operating at $499.16 \mathrm{MHz}$, with a three channel Bruker 4-mm HR-MAS probe integrated with a homospoil z'-gradient. The gradient was operated by a $40 \mathrm{~A}$ amplifier. The fast- and slow-sample spinning were carried out with MAS II at rate of 4000 and $500 \mathrm{~Hz}$, respectively, with \pm less than $2 \mathrm{~Hz}$. NMR spectra were collected with $16 \mathrm{k}$ time domain points, $20 \mathrm{ppm}$ sweep width, $1 \mathrm{~s}$ low-power presaturation pulse as a recycle delay, and with an echo time (TE $=2 \times \mathrm{N}$ number of rotor period $\left.\tau_{\mathrm{R}}\right)$ of $8 \mathrm{~ms}$ for the food phantom and $100 \mathrm{~ms}$ for the intact wasp. The number of accumulative scan was set to one-full phase cycling: 16 for HR-MAS CSI and 11 for HR-PASS CSI. In all CSI (including HR-PASS CSI) experiments, the gradient pulse length $(\delta)$ was set to a fixed value of $2 \mathrm{~ms}$ $\left(\mathrm{n} \cdot \tau_{\mathrm{R}}\right)$; subsequently, the desired field-of-view (FOV) was adjusted by the gradient steps $\mathrm{t} 1_{\mathrm{CSI}}$ together with the gradient amplitude $\mathrm{G}_{\mathrm{Z}}$ (i.e. FOV $=\left[\mathrm{t} 1_{\mathrm{CSI}}\right] \times\left[\mathrm{k}^{\cdot 1 \mathrm{H}} \gamma \cdot \delta \cdot \mathrm{G}_{\mathrm{Z}}\right]^{-1}$, $\mathrm{k}$ is a scaling factor which is calibrated experimentally with a rigid cylinder). All CSI experiments were performed with a FOV of $8.3 \mathrm{~mm}$ attributed by $64 \mathrm{t}_{\mathrm{CSI}}$ and $10 \%$ of $\mathrm{G}_{\mathrm{Z}}$ for the phantom; or $32 \mathrm{t}_{\mathrm{CSI}}$ with $5 \%$ for the wasp.

For the PASS sequence in HR-PASS CSI, 8-step $t 1_{\text {PASS }}$ was carried out. Consequently, a total of 8 consecutive 2D HR-PASS CSI spectra with identical CSI parameters $\left(\mathrm{t} 1_{\mathrm{CSI}}, \delta\right.$ and $\left.\mathrm{G}_{\mathrm{Z}}\right)$ were acquired, and each with a different set of interpulse delays for PASS. The delays can be found in Table 2 in [R.A. Wind et al., Prog. Nucl. Magn. Reson. Spectrosc., 2006, 49, 207.]

Data acquisitions and processing were carried out with the Bruker software package Topspin 3.2 and MATLAB.

For HR-PASS CSI, a summation of all 8 individual (i.e. 8-steps $\mathrm{t}_{\mathrm{PASS}}$ ) 2D FID was carried by a Topspin command 'adsu'. 
- The resultant summed F2 FID (i.e. chemical shift profile) was processed with zero filling and with an exponential apodization (with a $\mathrm{LB}=0.5 \mathrm{~Hz}$ ).

- The resultant summed F1 FID (i.e. spatial profile) was processed without 'zero' filling $\left(\mathrm{TD}=\mathrm{t} 1_{\mathrm{CSI}}\right)$ and with a Gaussian apodization $(\mathrm{LB}=-1 \mathrm{~Hz} ; \mathrm{GB}=0.5)$.

- A command ' $x f b$ ' in Topspin was applied to transform the summed 2D FID to the 2D spectrum with spatial profile in F1 and chemical shift in F2.

Each individual F2 slice projection spectrum was independently phased (except for those of wasp, which were phased with a magnitude mode), baseline correction 'abs', and referenced (to a doublet of alanine at $1.48 \mathrm{ppm}$ ). Peak assignments were assisted by Chenomx NMR suite 8.3, Human Metabolome Database Version 4.0 (www.hmbd.ca) and the corresponding references. Unfortunately, no supporting experiments (i.e. TOCSY, HSQC or J-RES) were performed to assist in the peak assignments.

\section{Heatmap analysis}

For each slice spectrum, $R_{\text {met }}$ can be estimated by the individual metabolic integral $\left(I_{m e t}\right): R_{m e t}=$ $\left[100 \% \times \mathrm{I}_{\text {met }}\right] /\left[\mathrm{N}_{\mathrm{H}-\mathrm{met}} \times \mathrm{I}_{\text {spectral sum }}\right]$, where $\mathrm{N}_{\mathrm{H}-\text { met }}$ is the number of corresponding protons, and $\mathrm{I}_{\text {spectral sum }}$ is the total integral between $0.5-8.7 \mathrm{ppm}$ excluding the water signal. This is followed by a colour coding scheme with red being the highest content and blue at zero. The peak integration of the individual metabolic signal (listed in Table S4) was carried out manually using MestreNova v8.1. It should be noted that the deduced $\mathrm{R}_{\text {met }}$ values should be considered as estimation because of the overlapping with the neighboring peaks.

\section{Multivariate data analysis}

The processed spectral data (by Topspin) were uploaded into MestreNova v8.1. The spectra (8.7 to $-0.5 \mathrm{ppm}$, excluding the water signal) were aligned. Each spectrum was divided into $0.02-\mathrm{ppm}$ buckets. The signal area under each bucket was integrated and normalized to a constant sum of all integrals. The resultant data in the matrix (sample $\times$ chemical shift bucket) correspond to observation and variable, respectively, of the model study. The matrix was exported to SIMCA P13 to proceed with the multivariate modeling. It was scaled using the Pareto scaling. Unsupervised PCA (principal component analysis) was performed. The models were validated by assessing the values of $R^{2} X, R^{2} Y$, and $Q^{2}$. 
a) HR-MAS CSI

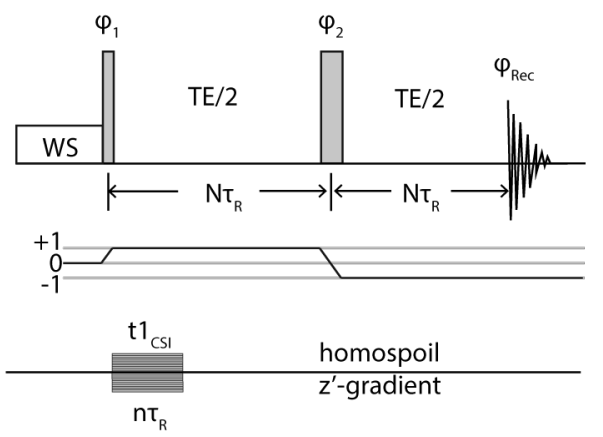

b) HR-PASS CSI

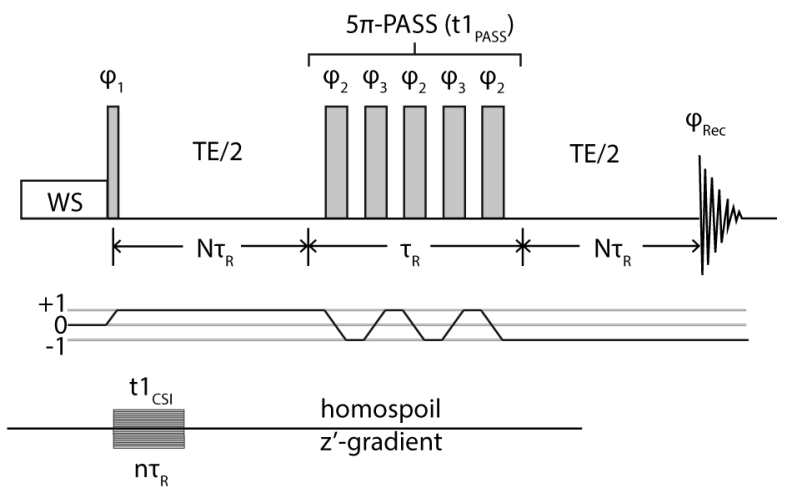

Fig S1. The NMR pulse sequence of (a) HR-MAS CSI and (b) HR-PASS CSI, along with the desired coherence transfer pathway which are determined by the phase cycling scheme: (a) $\varphi_{1}$ $=\left(\left\{0^{\circ}\right\}^{*} 4,\left\{180^{\circ}\right\}^{*} 4,\left\{90^{\circ}\right\}^{*} 4,\left\{270^{\circ}\right\}^{*} 4\right) ; \varphi_{2}=\left(0^{\circ}, 90^{\circ}, 180^{\circ}, 270^{\circ}\right) ; \varphi_{\mathrm{R}}=\left(0^{\circ}, 180^{\circ}, 0^{\circ}, 180^{\circ}\right.$, $180^{\circ}, 0^{\circ}, 180^{\circ}, 0^{\circ}, 270^{\circ}, 90^{\circ}, 270^{\circ}, 90^{\circ}, 90^{\circ}, 270^{\circ}, 90^{\circ}, 270^{\circ}$ ); and (b) 11-steps cogwheel scheme: $\varphi_{1}=90^{\circ} ; \varphi_{2}=(0,1,2,3,4,5,6,7,8,9,10) \times 2 \pi / 11 ; \varphi_{3}=0^{\circ}$ and $\varphi_{\mathrm{R}}=(0,6,1,7,2$, $8,3,9,4,10,5) \times 2 \pi / 11$. All interpulse delays are rotor synchronized $\left(\tau_{\mathrm{R}}\right)$, including the echo delay (TE), the gradient pulse and the ensemble composite $5 \pi$ in PASS. The PASS interpulse delays can be found in Table 2 in [R.A. Wind et al., Prog. Nucl.Magn.Reson. Spectrosc., 2006, 49, 207.] The Bruker Topspin pulse sequences (HR-MAS CSI and HR-PASS CSI) are available upon request [alan.wong@cea.fr]. 

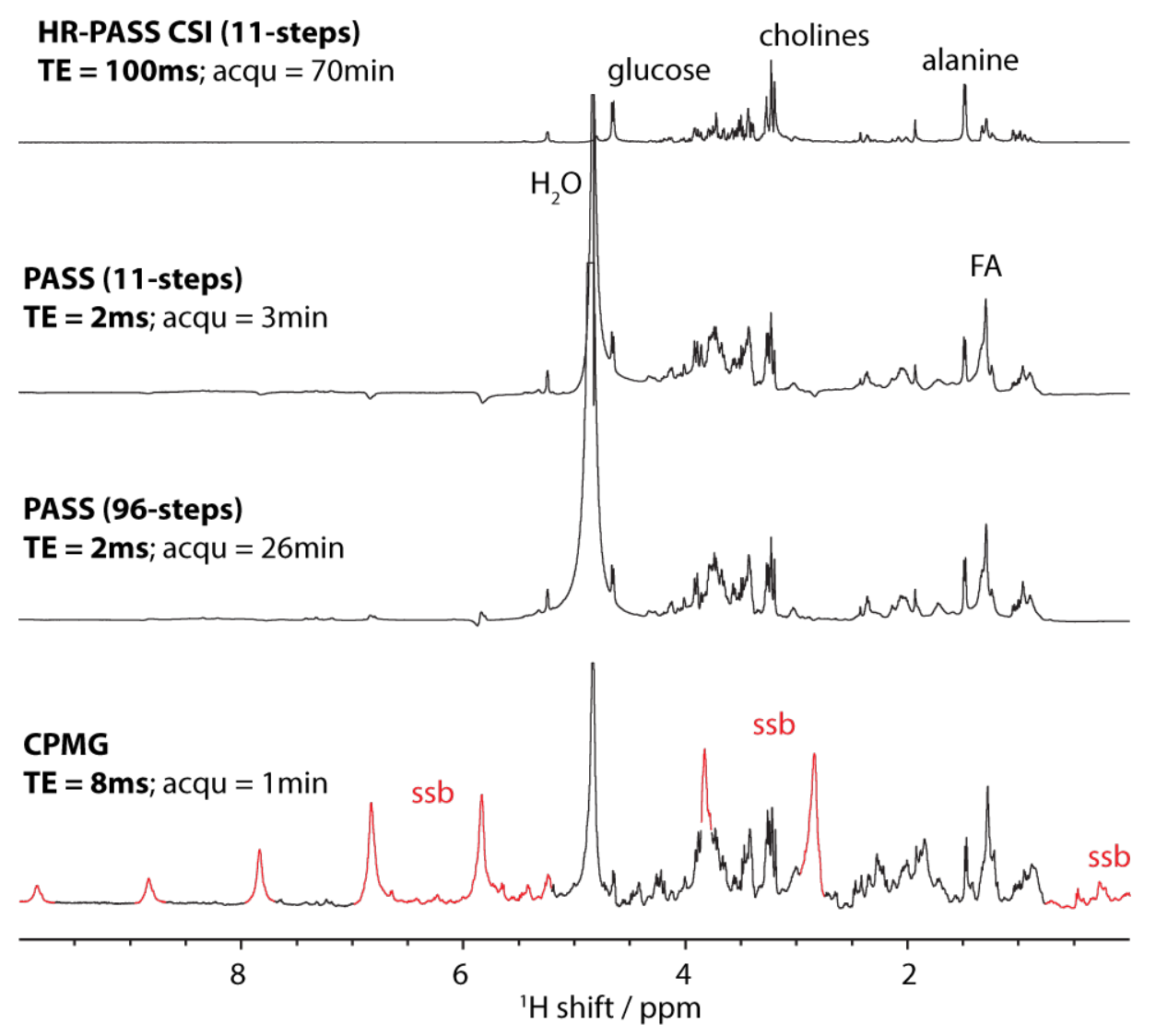

Fig S2 WASP. ${ }^{1} \mathrm{H}$ spectra (at $500 \mathrm{MHz}$ ) of an intact wasp (a sacrificed wasp used only for the experimental setup) spinning at $500 \mathrm{~Hz}$. It illustrates the effect of the PASS experiment and the efficiency with the different phase-cycling scheme. Moreover, it also shows the impact of a long TE (100 ms) on the $\mathrm{H}_{2} \mathrm{O}$ and fatty acids signals and their ssb. 


\section{F1 summed projection}

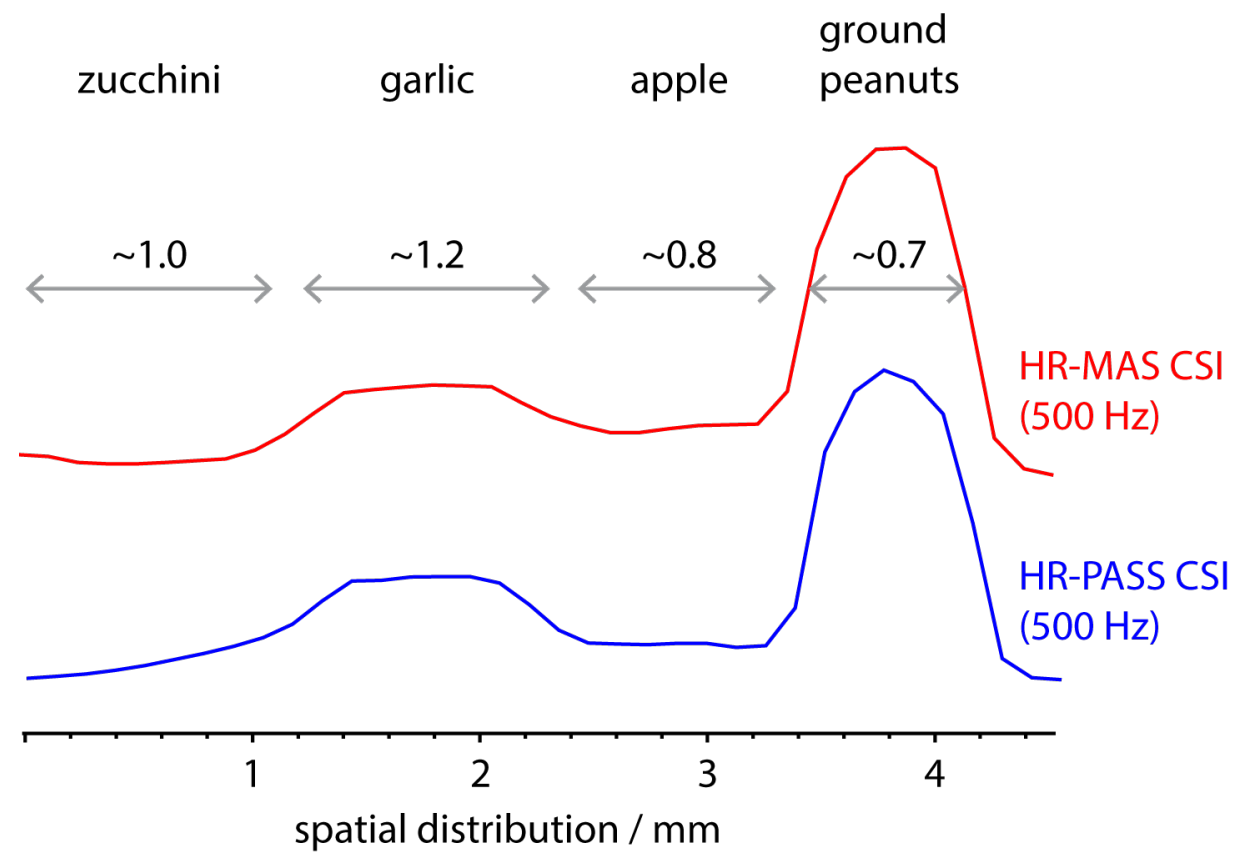

Fig S3 Phantom. The F1 summed projection (i.e. ${ }^{1} \mathrm{H}$ density spatial profile). It shows the distant spatial profile for the different food layers along $\mathrm{z}$ '. 


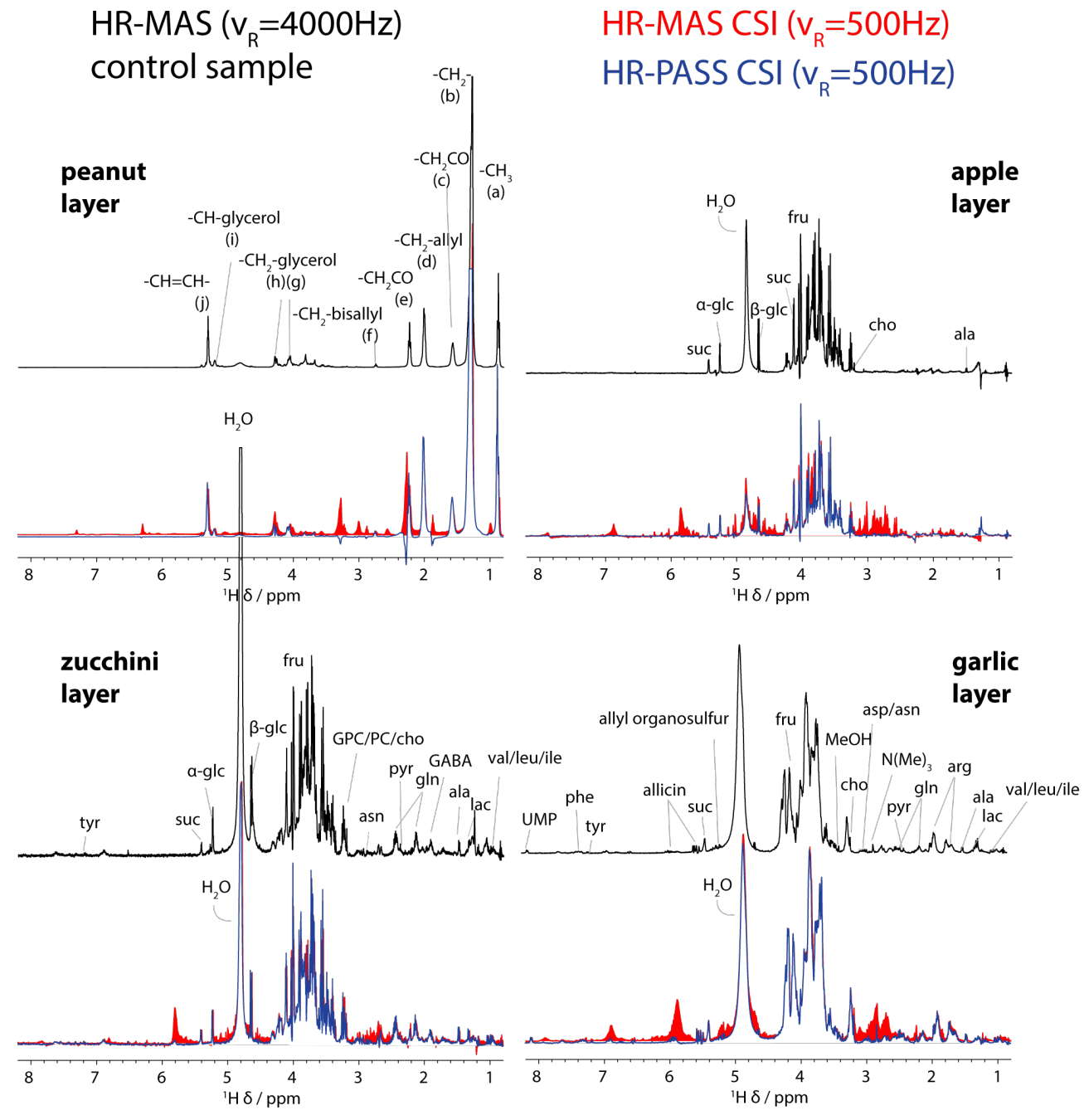

Fig S4 Phantom. ${ }^{1} \mathrm{H}$ spectral comparisons of the individual food layers. It demonstrates the ssb suppression on each layer with HR-PASS CSI. Moreover, the resultant HR-PASS CSI spectra (blue) correspond well with the HR-MAS NMR spectra (black) of the individual control samples. The tentative peak assignments are summarized in Table S1 and S2. 


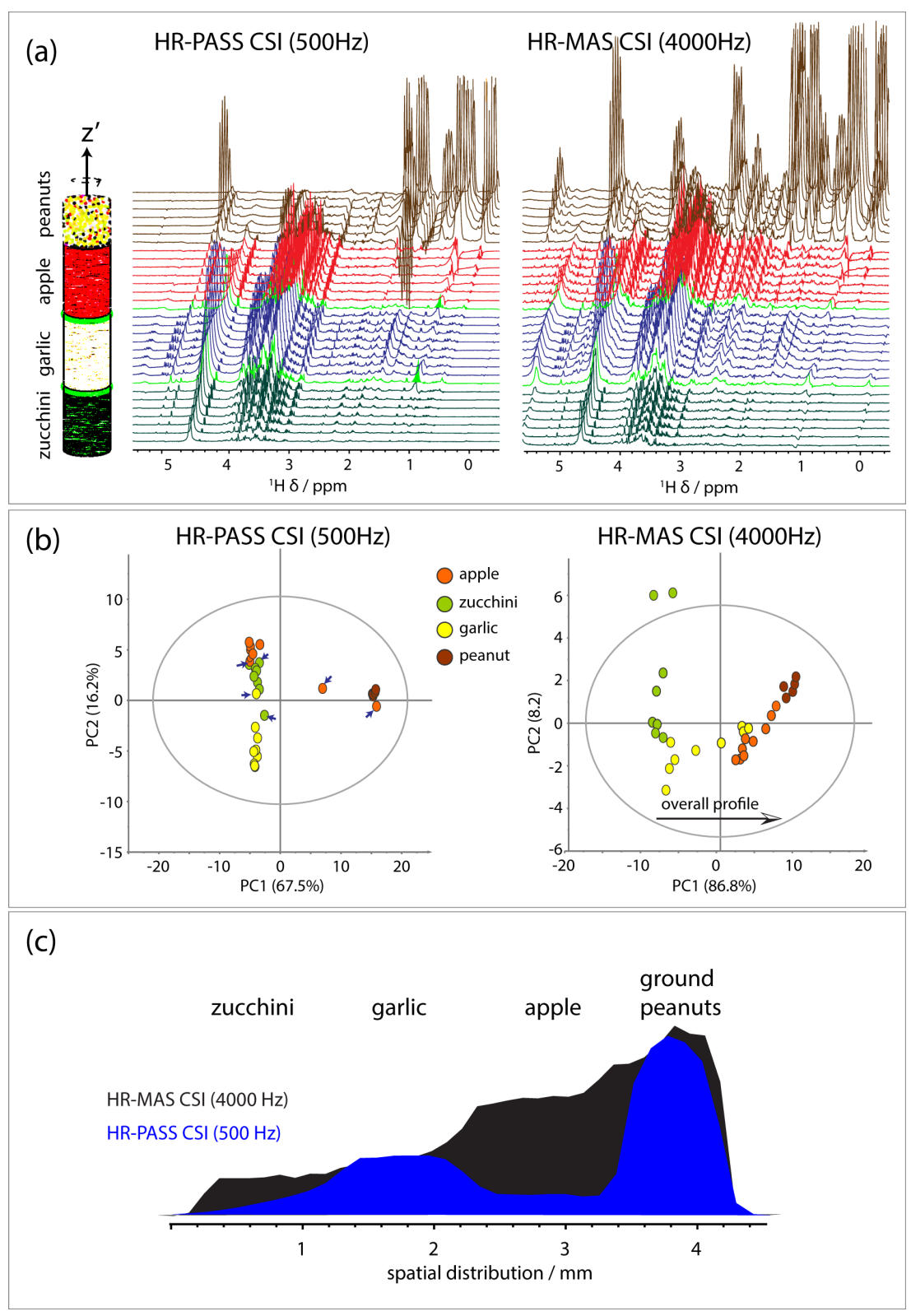

Fig S5 Phantom. Comparison between slow (500 Hz, top) and fast (4000 Hz, bottom) spinning: (a) Stacked plots of the slice spectra; and its (b) PCA with $\mathrm{R}^{2} \mathrm{X}=0.976, \mathrm{Q}^{2}=0.94$ for the slow spinning data, and with $\mathrm{R}^{2} \mathrm{X}=0.993, \mathrm{Q}^{2}=0.978$ for the fast spinning data; and (c) $\mathrm{F} 1$ summed projection (i.e. spatial profile).

The results $(\mathrm{a}, \mathrm{b})$ clearly show that the metabolic profiles are different between the slow and fast spinning. The blur arrows in the PCA of HR-PASS CSI (in b) indicate the interfaced spectral data between the layers. The black arrow in the PCA of HR-MAS CSI (in b) shows the directional changes in the individual spectral profile. (c) Shows the overall displacement of the metabolic fluids. 
a) HR-PASS CSI TE $=100 \mathrm{~ms}$

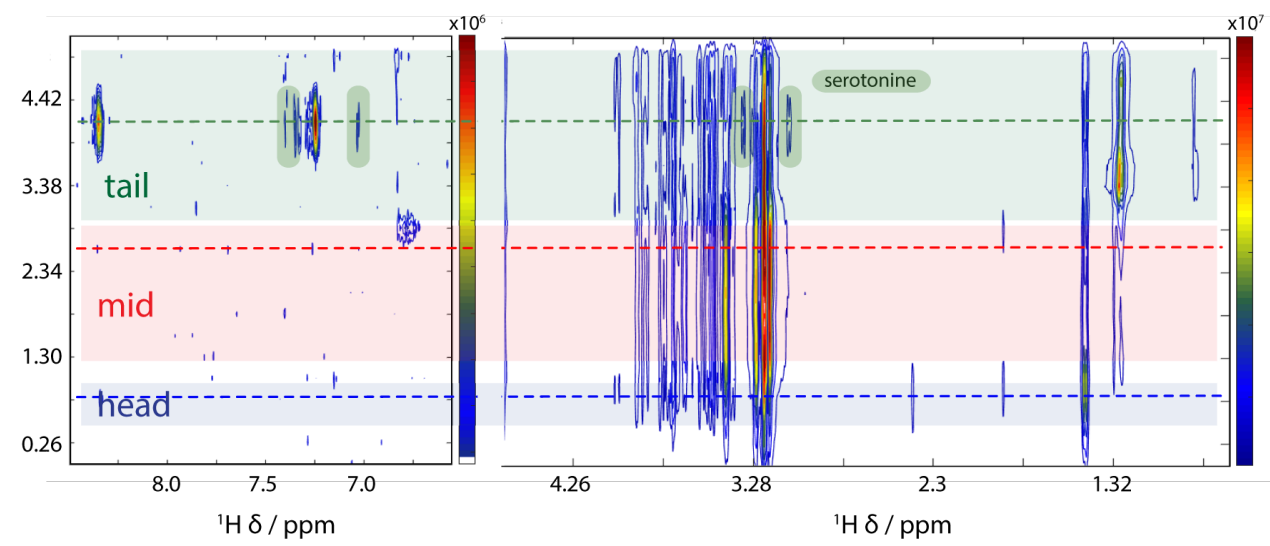

b) F2 sliced spectra

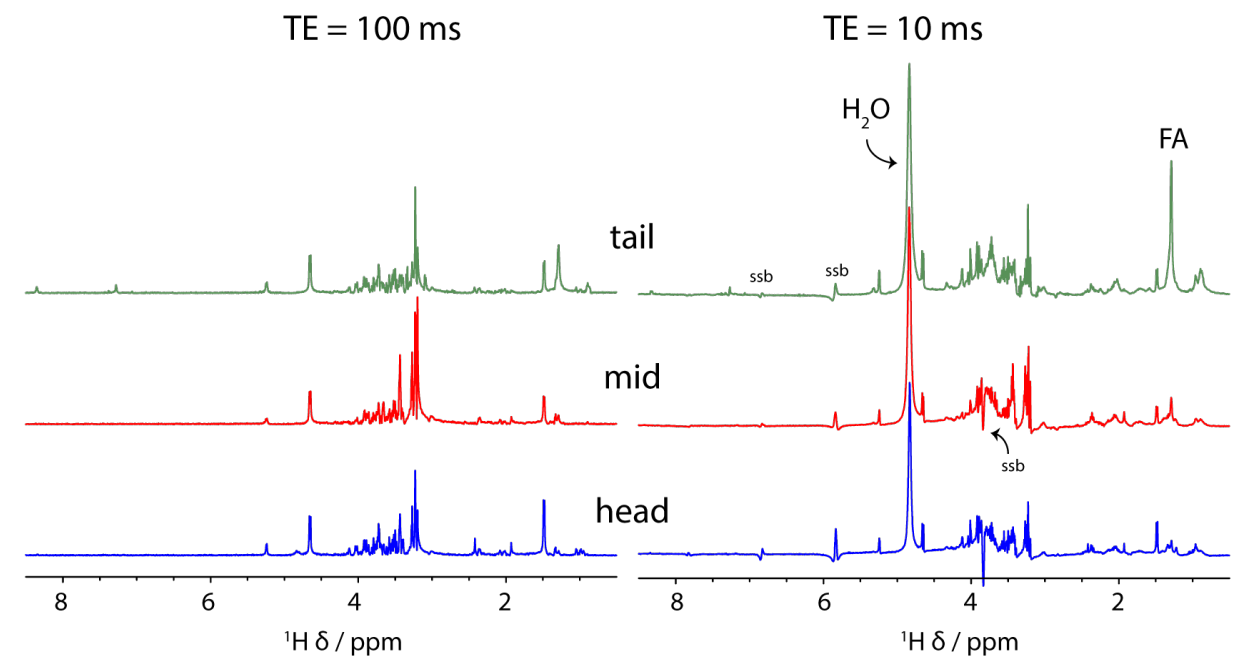

Fig S6 Wasp. (a) ${ }^{1} \mathrm{H}$ HR-PASS CSI. A 2D contour plot showing the different anatomical sections. A significant venom metabolite, serotonine, has been identified in the tail section. (b) Spectral comparison of the different TE on a scarified intact wasp (i.e. Fig S2). It shows the effect of long TE (with $100 \mathrm{~ms}$ ) for suppressing both the isotopic and ssb of $\mathrm{H}_{2} \mathrm{O}$ and fatty acids. 


\section{Heatmap comparison}
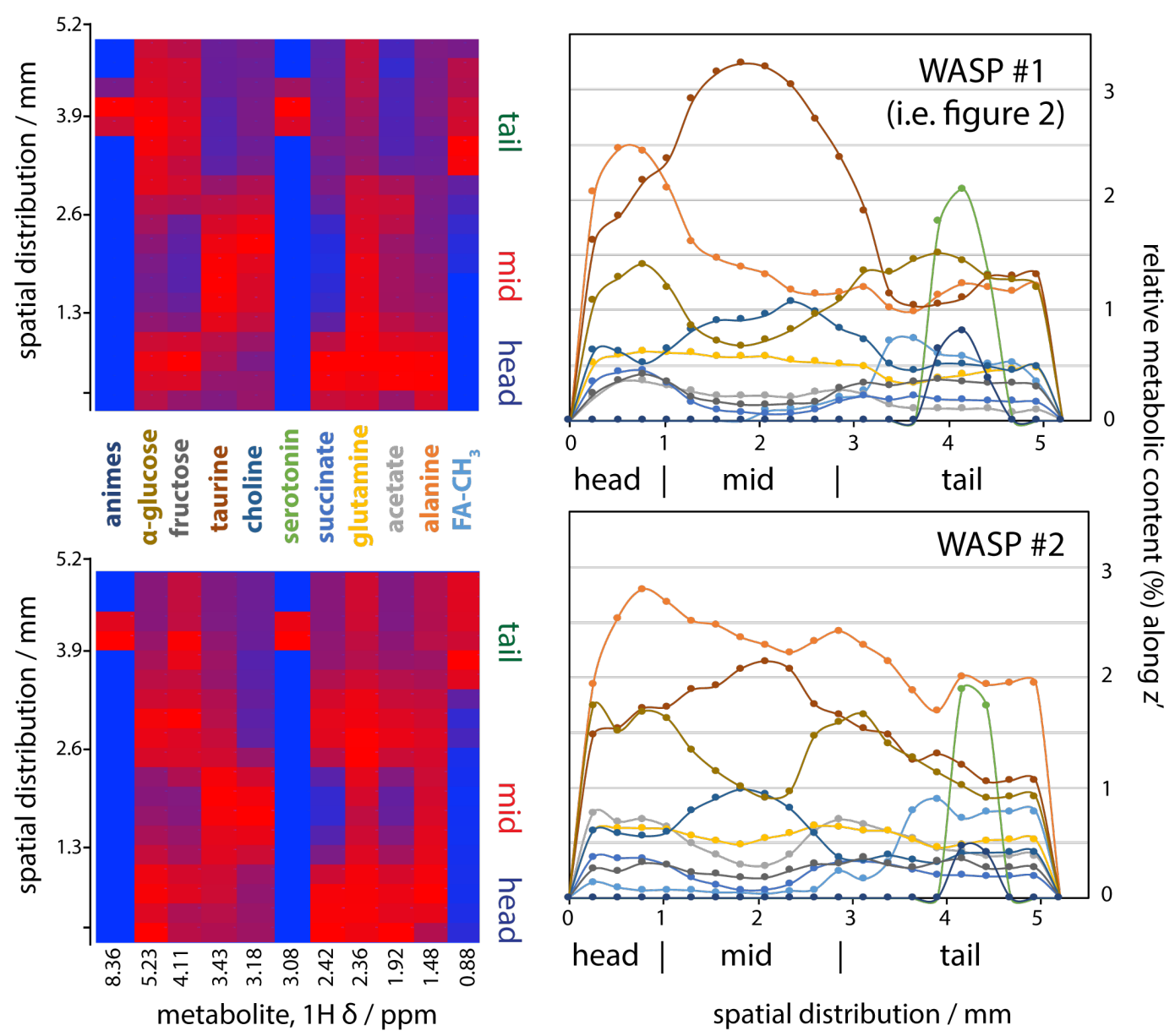

Fig S7 Wasp. Heatmap comparison between wasp \#1 (top) vs \#2 (bottom). The data of wasp $\# 1$ are discussed in the text (i.e. Fig 2). The color lines in the z' projection corresponds to those labelled in the heatmap. Note that the venom metabolites (i.e serotonin) are located in the tail section. 


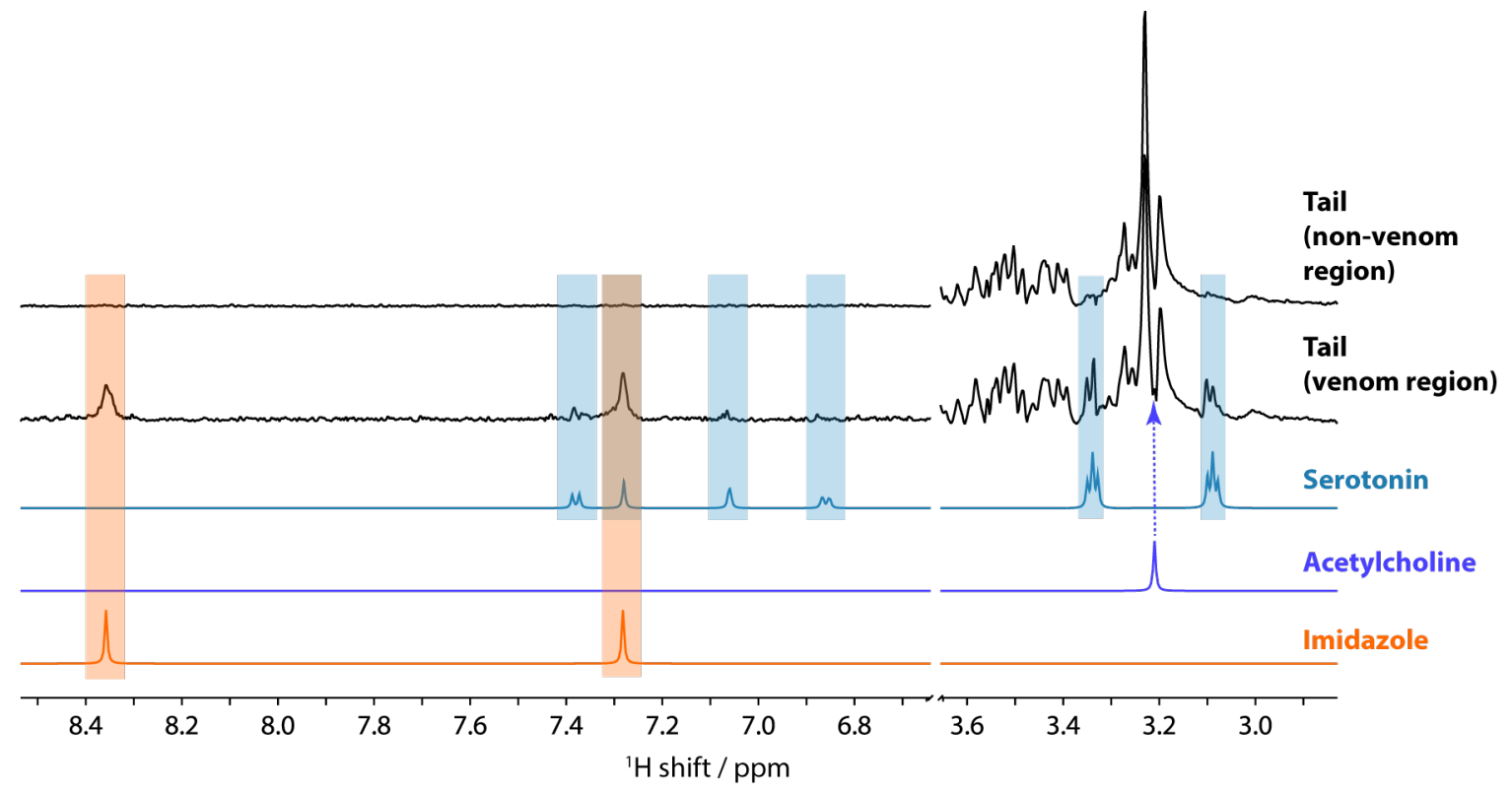

Fig S8 Wasp. Peak fitting, by Chenomx NMR, on the F2 slice spectra of the tail section in HRPASS CSI. It shows the peak assignments of the two known venom metabolites (serotonin and acetylcholine), and also a 'possible' amine-derivatives (imidazole). Unfortunately, the study did not acquire supporting NMR spectra (such as TOCSY or HSQC or J-res) to confirm the assignments; however, the above fittings (especially for serotonin) offer a good level of confidence in the assignments. 
Table S1: Tentative peak assignments from the individual HR-PASS CSI slice spectra of zucchini, garlic and apple

\begin{tabular}{|c|c|c|c|c|}
\hline $\begin{array}{l}\text { Peak } \quad[\mathrm{ppm}] \\
\text { (multiplicity) }\end{array}$ & Metabolite & Zucchini & Garlic & Apple \\
\hline $0.94(\mathrm{t})$ & Leucine (leu) & $\mathrm{x}$ & $\mathrm{x}$ & $\mathrm{x}$ \\
\hline $0.96(t)$ & Isoleucine (ile) & $\mathrm{x}$ & $\mathrm{x}$ & - \\
\hline $1.04(d)$ & Valine (val) & $\mathrm{x}$ & $\mathrm{x}$ & - \\
\hline $1.18(\mathrm{t})$ & unknown & $\mathrm{x}$ & $\mathrm{x}$ & $\mathrm{x}$ \\
\hline $1.33(\mathrm{~d})$ & Lactate (lac) & $\mathrm{x}$ & $\mathrm{x}$ & $\mathrm{x}$ \\
\hline $1.48(\mathrm{~d})$ & Alanine (ala) & $\mathrm{x}$ & $\mathrm{x}$ & $\mathrm{x}$ \\
\hline $1.91(\mathrm{~m})$ & Arginine (arg) & very low & $\mathrm{x}$ & - \\
\hline $2.3(\mathrm{t})$ & GABA & $\mathrm{x}$ & - & $\mathrm{x}$ \\
\hline $2.14(\mathrm{~m}), 2.45(\mathrm{~m})$ & Glutamine $(g \ln )$ & $\mathrm{x}$ & $?$ & - \\
\hline $2.38(\mathrm{~s})$ & Pyruvic & - & $\mathrm{x}$ & - \\
\hline 2.37 (dd), $2.67(\mathrm{dd})$ & Malic & $?$ & - & $?$ \\
\hline $2.4(\mathrm{~s})$ & Succinate & $?$ & - & - \\
\hline $2.85(\mathrm{~s})$ & $\mathrm{N}(\mathrm{Me}) 3$ & - & $\mathrm{x}$ & - \\
\hline $2.86(\mathrm{dd}), 2.96(\mathrm{dd})$ & $\begin{array}{l}\text { Asparagine } \\
\text { (asn) }\end{array}$ & $\mathrm{x}$ & - & $\mathrm{x}$ \\
\hline $3.36(\mathrm{~s})$ & methonal & $\mathrm{x}$ & $\mathrm{x}$ & $\mathrm{x}$ \\
\hline $4.11(\mathrm{~m})$ & Fructose (fru) & $\mathrm{x}$ & $\mathrm{x}$ & $\mathrm{x}$ \\
\hline $4.64(\mathrm{~d}), 5.2(\mathrm{~d})$ & Glucose (glc) & $\mathrm{x}$ & $\mathrm{x}$ & $\mathrm{x}$ \\
\hline $5.42(\mathrm{~d})$ & Sucrose & $\mathrm{x}$ & $\mathrm{x}$ & $\mathrm{x}$ \\
\hline $5.54(\mathrm{~m})$ & Allicin & - & $\mathrm{x}$ & - \\
\hline $6.53(\mathrm{~s})$ & Fumarate & $\mathrm{x}$ & $\mathrm{x}$ & - \\
\hline 6.9 (d), $7.2(\mathrm{~d})$ & Tyrosine (tyr) & $\mathrm{x}$ & $\mathrm{x}$ & - \\
\hline 7.3-7.4 (m) & Phenylalanine & $\mathrm{x}$ & $\mathrm{x}$ & - \\
\hline $8.11(\mathrm{~s})$ & UMP & - & $\mathrm{x}$ & - \\
\hline
\end{tabular}

Abbreviation: 'x' present; '?' questionable; '-' not present; (s) singlet; (d) doublet; (t) triplet; (m) multiple; GABA $\gamma$-aminobutyric acid; UMP Uridine monophosphate

Blue font: Peak used in the heatmap analysis

Reference: [apple] Martina Vermathen, Mattia Marzorati, Gaëlle Diserens, Daniel Baumgartner, Claudia Good, Franz Gasser, Peter Vermathen, Metabolic profiling of apples from different production systems before and after controlled atmosphere (CA) storage studied by ${ }^{1} \mathrm{H}$ high resolution-magic angle spinning (HR-MAS) NMR, Food Chemistry 2017, 233, 391400; [garlic] (a) Tingfu Liang, Feifei Wei, Yi Lu, Yoshinori Kodani, Mitsuhiko Nakada, Takuya Miyakawa, and Masaru Tanokura, Comprehensive NMR Analysis of Compositional Changes of Black Garlic during Thermal Processing, J. Agric. Food Chem. 2015, 63, 683-691; (b) Covadonga Lucas-Torres, Gaspard Huber, Atsuyuki Ichikawa, Yusuke Nishiyama, Alan Wong, HR- $\mu$ MAS NMR-Based Metabolomics: Localized Metabolic Profiling of a Garlic Clove with $\mu \mathrm{g}$ Tissues, Anal. Chem. 2018, 90, 13736-13743. [zucchini] Ana Cristina Abreu, Luis Manuel Aguilera-Saéz, Araceli Peña, Mar García-Valverde, Patricia Marín, Diego L. Valera, Ignacio Fernańdez, NMR-Based Metabolomics Approach To Study the Influence of Different Conditions of Water Irrigation and Greenhouse Ventilation on Zucchini Crops, $J$. Agric. Food Chem. 2018, 66, 8422-8432. 
Table S2: Tentative peak assignments from the individual HR-PASS CSI slice spectra of peanut

\begin{tabular}{ll}
\hline Peak [ppm] & FA-peak \\
\hline 0.88 & -CH3 \\
\hline 1.28 & $-\mathrm{CH} 2-$ \\
1.58 & $-\mathrm{CH} 2 \mathrm{bCO}$ \\
2.02 & $-\mathrm{CH} 2$-allyl \\
\hline 2.25 & $-\mathrm{CH} 2 \mathrm{aCO}$ \\
2.75 & $-\mathrm{CH} 2$-bisallyl \\
\hline 3.7 & $?$ \\
\hline 3.83 & $?$ \\
\hline 4.07 & $-\mathrm{CH} 2$-glycerol \\
\hline 4.28 & $-\mathrm{CH} 2$-glycerol \\
\hline 5.21 & $-\mathrm{CH}-$ glycerol \\
\hline 5.32 & $-\mathrm{CH}=\mathrm{CH}-$ \\
\hline
\end{tabular}

Abbreviation: '?' questionable

Blue font: Peak used in the heatmap analysis.

The shift range are summarized in Tab S4. 
Table S3: Tentative peak assignments from the individual HR-PASS CSI slice spectra of head, mid and tail section (excluding the fatty acid peaks)

\begin{tabular}{|c|c|c|c|c|}
\hline Metabolite & peak (ppm) & Head & Mid & Tail \\
\hline Leucine (leu) & 0.96 & $\mathrm{X}$ & - & - \\
\hline Isoleucine (ile) & 1.00 & $\mathrm{x}$ & - & - \\
\hline Valine (val) & 1.02 & $\mathrm{x}$ & - & $\mathrm{x}$ \\
\hline Lactate (lac) & 1.33 & $\mathrm{x}$ & $\mathrm{x}$ & $\mathrm{x}$ \\
\hline Alanine (ala) & 1.48 & $\mathrm{x}$ & $\mathrm{x}$ & $\mathrm{x}$ \\
\hline Acetate (ace) & 1.92 & $\mathrm{x}$ & $\mathrm{x}$ & - \\
\hline Glutamate & $2.03,2.35$ & $\mathrm{x}$ & $\mathrm{x}$ & $\mathrm{x}$ \\
\hline Succinate (suc) & 2.42 & $\mathrm{x}$ & - & $\mathrm{x}$ \\
\hline Serotonin* & $\begin{array}{l}3.08, \quad 3.35, \\
6.86, \quad 7.06, \\
7.27,7.37\end{array}$ & - & - & $\mathrm{x}$ \\
\hline Choline (cho) & 3.19 & $\mathrm{x}$ & $\mathrm{x}$ & $\mathrm{x}$ \\
\hline Acetylcholine (ACh) & $3.20,3.73$ & - & - & $\mathrm{x}$ \\
\hline Phosphocholine (PC) & 3.20 & $\mathrm{x}$ & $\mathrm{x}$ & - \\
\hline $\begin{array}{l}\text { Glycerophosphocholine } \\
\text { (GPC) }\end{array}$ & 3.22 & $\mathrm{x}$ & $\mathrm{x}$ & $\mathrm{x}$ \\
\hline Taurine (tau) & $3.26,3.43$ & $x$ & $x$ & - \\
\hline$\beta$-glucose $(\beta$-glc $)$ & 4.65 & $\mathrm{x}$ & $\mathrm{x}$ & $\mathrm{x}$ \\
\hline $\begin{array}{l}\alpha \text {-glucose }(\alpha-\text { glc }) \\
\text { / or trehalose }\end{array}$ & 5.24 & $\mathrm{x}$ & $\mathrm{x}$ & $\mathrm{x}$ \\
\hline Fructose & $\begin{array}{l}4.11, \quad 4.04, \\
4.01\end{array}$ & $\mathrm{x}$ & - & $\mathrm{X}$ \\
\hline $\begin{array}{l}\text { Venom active animes } \\
\text { (imidazole ?)* }\end{array}$ & $7.27,8.34$ & - & - & $\mathrm{x}$ \\
\hline
\end{tabular}

Abbreviation: 'x' present; '?' questionable; '-' not present;

* according to Chenomx Profiler assignment (Fig S9)

Blue font: Peak used in the heatmap analysis. The shift range are summarized in Table S4.

Reference: [1] Moreno M, Giralt, E. Three valuable peptides from bee and wasp venoms for therapeutic and biotechnological use: Melittin, apamin and mastoparan. Toxins (Basel). 2015, 7, 1126-1150; [2] Kapranas A, Snart CJP, Williams H, Hardy ICW, Barrett DA. Metabolomics of aging assessed in individual parasitoid wasps. Sci Rep. 2016, 6, 34848. 
Table S4: The chemical shift range used for the signal integration $\mathrm{I}_{\text {met }}$ in the heatmap.

\begin{tabular}{|c|c|c|c|}
\hline Metabolite & $\begin{array}{ll}\text { Range } & \text { [ppm] } \\
\text { (multiplicity) } & \end{array}$ & Metabolite & $\begin{array}{l}\text { Range }[\mathrm{ppm}] \\
\text { (multiplicity) }\end{array}$ \\
\hline Food phantom & & WASP \#1 & \\
\hline Tyrosine & $7.23-7.16(\mathrm{~d})$ & Anime? & $8.40-8.32(\mathrm{~s})$ \\
\hline Fumarate & $6.33-6.52(\mathrm{~s})$ & Glucose & $5.26-5.21(\mathrm{~d})$ \\
\hline Allicin & $5.60-5.47(4 \mathrm{~s})$ & Fructose & $4.14-4.10(\mathrm{br})$ \\
\hline Sucrose & $5.45-5.38(d)$ & Taurine & $3.45-3.41(\mathrm{t})$ \\
\hline UFA & $5.37-5.25(\mathrm{~s})$ & Choline & $3.21-3.16(\mathrm{~s})$ \\
\hline Glyercol & $5.24-5.17(\mathrm{~s})$ & Serotonin & $3.11-3.05(\mathrm{t})$ \\
\hline Glucose & $4.67-4.61(\mathrm{~d})$ & Succinate & $2.44-2.40(\mathrm{~s})$ \\
\hline Fructose & $4.13-4.1$ (br) & Glutamine & $2.39-2.32(\mathrm{~m})$ \\
\hline Methanol & $3.37-3.35(\mathrm{~s})$ & Acetate & $1.94-1.90(\mathrm{~s})$ \\
\hline Choline & $3.20-3.17(\mathrm{~s})$ & Alanine & $1.50-1.45(\mathrm{~d})$ \\
\hline $\mathrm{N}(\mathrm{Me})_{3}$ & $2.86-2.83(\mathrm{~s})$ & $\mathrm{FA}-\mathrm{CH}_{3}$ & $0.92-0.85$ (br) \\
\hline Pyruvate & $2.39-2.37(\mathrm{~s})$ & & \\
\hline Glutamine & $2.20-2.10(\mathrm{~m})$ & & \\
\hline Arginine & $1.96-1.86(\mathrm{~m})$ & & \\
\hline Alanine & $1.50-1.46(\mathrm{~d})$ & & \\
\hline $\mathrm{FA}-\mathrm{CH}_{2}$ & $1.32-1.24$ (br) & & \\
\hline Valine & $1.06-1.02(\mathrm{~d})$ & & \\
\hline $\mathrm{FA}-\mathrm{CH}_{3}$ & $0.91-0.86$ (br) & & \\
\hline
\end{tabular}

Abbreviation: (s) singlet; (d) doublet; (t) triplet; (m) multiple; (br) broad 